\title{
Bulk and Single-Cell Next-Generation Sequencing: Individualizing Treatment for Colorectal Cancer
}

\author{
Ioannis D. Kyrochristos ${ }^{1,2}$, Demosthenes E. Ziogas 1,3, Anna Goussia ${ }^{4}$, \\ Georgios K. Glantzounis ${ }^{2}$ and Dimitrios H. Roukos ${ }^{1,2,5, *}$ \\ 1 Centre for Biosystems and Genome Network Medicine, Ioannina University, 45110 Ioannina, Greece; \\ ikyrochristos@hotmail.com (I.D.K.); deziogas@hotmail.com (D.E.Z.) \\ 2 Department of Surgery, Ioannina University Hospital, 45500 Ioannina, Greece; gglantzounis@gmail.com \\ 3 Department of Surgery, 'G. Hatzikosta' General Hospital, 45001 Ioannina, Greece \\ 4 Department of Pathology, Ioannina University Hospital, 45500 Ioannina, Greece; goussiaanna@gmail.com \\ 5 Department of Systems Biology, Biomedical Research Foundation of the Academy of Athens (BRFAA), \\ 11527 Athens, Greece \\ * Correspondence: droukos@uoi.gr; Tel.: +302651005572
}

Received: 5 November 2019; Accepted: 14 November 2019; Published: 18 November 2019

\begin{abstract}
The increasing incidence combined with constant rates of early diagnosis and mortality of colorectal cancer (CRC) over the past decade worldwide, as well as minor overall survival improvements in the industrialized world, suggest the need to shift from conventional research and clinical practice to the innovative development of screening, predictive and therapeutic tools. Explosive integration of next-generation sequencing (NGS) systems into basic, translational and, more recently, basket trials is transforming biomedical and cancer research, aiming for substantial clinical implementation as well. Shifting from inter-patient tumor variability to the precise characterization of intra-tumor genetic, genomic and transcriptional heterogeneity (ITH) via multi-regional bulk tissue NGS and emerging single-cell transcriptomics, coupled with NGS of circulating cell-free DNA (cfDNA), unravels novel strategies for therapeutic response prediction and drug development. Remarkably, underway and future genomic/transcriptomic studies and trials exploring spatiotemporal clonal evolution represent most rational expectations to discover novel prognostic, predictive and therapeutic tools. This review describes latest advancements and future perspectives of integrated sequencing systems for genome and transcriptome exploration to overcome unmet research and clinical challenges towards Precision Oncology.
\end{abstract}

Keywords: colorectal cancer; genomic and transcriptomic landscapes; intra-tumor heterogeneity; liquid biopsies; next-generation sequencing

\section{Introduction}

The validity of next-generation sequencing (NGS) at both bulk and single-cell levels in the identification of disease associated variants and tumor heterogeneity has transformed biomedical and cancer research [1-6]. The precise characterization of genetic heterogeneity with targeted NGS (tNGS) and whole-exome sequencing (WES), genomic variation with whole-genome sequencing (WGS) and transcriptional variability with RNA sequencing (RNAseq) and chromatin immunoprecipitation sequencing (ChIP-seq) has provided new knowledge on tumorigenesis, metastasis, drug response and relapse [7-12].

Although conventional research on the basis of tumor homogeneity and stability, as well as the linear single-gene transcription concept, has improved oncological outcomes for colorectal cancer (CRC) patients through the standardization of diagnosis, TNM staging and multimodal treatment, major clinical challenges remain unresolved $[13,14]$. Indeed, 50 years after the declaration of war on cancer [15] malignancy remains a principal cause of death in the industrialized world [16]. The valid identification of intra-tumor heterogeneity (ITH) at bulk and single-cell resolution, in conjunction 
with NGS of matched circulating cell-free DNA (cfDNA-NGS) are revolutionizing cancer science, creating new exciting opportunities to individualize therapy and substantially reduce oncological events [8,17-19]. Indeed, progress has been so rapid that these discoveries have already been translated into early-phase clinical trials $[17,20]$. Moreover, evidence on extensive inter- and intra-patient genetic, genomic and transcriptional heterogeneity [7-9] has underlined the need for combinatorial targeted therapy to improve the rates of disease-free, progression-free and overall survival [17,20-22]. This review discusses latest science advances, bottlenecks and future capabilities of genomic and transcriptomic landscape dissection in time and space towards precise prediction of drug response and tailored treatment for sporadic colorectal cancer.

\section{Advances and Limitations in the Management of Colorectal Cancer}

Colorectal cancer is currently the third most common cancer type, with over 1.8 million new diagnosed cancers, and the second leading cause of cancer-related mortality, accounting for over 881,000 deaths, in 2018 worldwide [16]. Considering the corresponding figures in 2012 (1.4 million cases and 693,900 deaths respectively), one can extract meaningful conclusions [23]. First, the substantial increase in incidence suggests lack of effective primary preventive strategy development, and second, despite a statistical survival improvement over time in the Western world [13], mortality/incidence ratio remains unchanged. These facts reflect the slow progress of conventional research and clinical practice regarding prevention and standardized multimodal treatment of CRC over the 50-year long war on cancer $[15,24]$. Nowadays, development of targeted therapies is still guided by the central dogma of molecular biology on linear transcription from single genes to mRNAs to proteins [24,25]. Moreover, all diagnostic approaches according to recent guidelines for treatment are based on pathohistological single-biopsy diagnosis, centered around the hypothesis of tumor homogeneity and stability [14].

Surgery aiming to complete tumor resection (R0) remains the fundamental principle of treatment with curative intent, even for patients with resectable liver and/or lung metastatic deposits, contrary to most other major cancer types $[14,26]$. Primary tumor localization in the colon or rectum is critical for therapeutic decision making. Adjuvant chemotherapy is indicated in most colon cancer patients [14]. By contrast, peri-operative treatment is suggested to most rectal cancer patients, including neo-adjuvant chemo-radiotherapy (NAC) followed by surgery and adjuvant chemotherapy (AC) [14]. However, an appropriate large-scale randomized controlled trial (RCT) has demonstrated no 10-year survival benefit from AC following NAC/surgery, particularly for patients with ypT0-2 disease (post-surgery staging after NAC) [27]. Thus, patients with ypT0-2 stage could potentially be spared the adverse effects associated with $\mathrm{AC}$ but further confirmation trials are required.

In contrast to modern non-targeted standard surgery, radiotherapy and chemotherapy, tumor-directed therapy with targeted drugs has recently surfaced as a rational hope to improve oncological outcomes of cancer patients [14]. However, the expectations of reducing relapse and cancer-related death rates through the addition of targeted agents to treatment regimens have not yet been met for resectable CRC. Indeed, high-quality evidence from RCTs suggests equal survival among resected stage II/III colon cancer patients treated with AC with or without targeted drugs [28,29], while for patients with resected CRC liver metastases progression-free survival was significantly shorter after the addition of cetuximab to standard AC [30].

Improvement of oncological outcomes via the standardization of multimodal treatment, including R0 surgery plus AC/NAC, has rather decelerated over the past decade $[13,14,16,31]$, thus limiting expectations for further progress in the near future via conventional research-based clinical practice. An apparent innovative research strategy is primarily provided by latest scientific advances in genome and transcriptome exploration in time and space.

\section{Next-Generation Sequencing: Progress from Static to Saptiotemporal Genomic and Transcriptomic Analyses}

Next-generation sequencing (NGS) has brought a biotechnological revolution upon the study of genomic and transcriptomic variation, offering unprecedented accuracy, speed, and affordability at the 
same time. These advantages have led to the successful incorporation of NGS into the ENCODE [32], Mouse ENCODE [33] and modENCODE [34] projects exploring coding and non-coding genome functionality and gene expression regulation, as well as the exploitation of NGS systems within two very large-scale cancer consortia, namely The Cancer Genome Atlas (TCGA) [35] and the International Cancer Genome Consortium (ICGC) [36]. The applications of NGS span over several distinct sequencing systems. First, targeted NGS (tNGS) allows for rapid and accurate sequencing of a known-gene panel to detect specific cancer-related alterations at a very low cost, which has led to its widespread utilization in both laboratory and clinical settings. Second, whole-exome sequencing (WES) analyses the protein-coding region of genes accounting for $1.5 \%$ of the total genome, thus emphasizing on structural coding variants. Third, whole-genome sequencing (WGS) scans all coding and non-coding parts of the genome, enabling the identification of functional non-coding elements associated with disease. Fourth, RNA sequencing (RNAseq) or whole-transcriptome sequencing is used to characterize the structure and dynamics of the transcriptome and track gene expression with the capacity to discover novel molecular classifications $[37,38]$. Finally, chromatin immunoprecipitation sequencing (ChIP-Seq) enables genome-wide mapping of protein-DNA interactions by combining chromatin immunoprecipitation (ChIP) with NGS to identify the binding sites of transcription factors aiming to enhance our understanding of transcriptional regulation [39]. All methods have been extensively applied by numerous studies on both static and dynamic patient-derived samples to explore cancer evolution in time and space. Colorectal cancer represents a prime paradigm of explosive research progress, due to the high threat level it poses to public health on the one hand and the accessibility of both primary and metastatic tumor specimens on the other.

\subsection{Single-Biopsy Genomics and Transcriptomics}

Table 1 [7,40-55] summarizes most valid studies investigating genomic and transcriptomic colorectal cancer landscapes, as well as inter-patient heterogeneity, via the static analysis of single biopsies. Following the introduction of specific recommendations for large sample sizes to ensure the validity of genomic discovery of cancer genes and targetable mutations by Lawrence et al. in 2014 [7], several studies with significant samples sizes have emerged. Beyond confirmation of previous discoveries, numerous novel tumor-specific recurrently mutated and cancer driver genes were identified through whole-exome or genome analysis, both for sporadic as well as for familial CRC, including some that had not been implicated in any cancer type before, such as genes related to proliferation, apoptosis, genome stability, chromatin regulation, immune evasion, RNA processing and protein homeostasis. [7,42,43,51,52,55]. Apart from hypermutated tumors, comprehensive integrative analysis of CRC tumor/normal pairs revealed that cancers arising in the colon and rectum harbor highly similar genomic alterations, such as copy numbers, and most of the hypermutated tumors originate in the right colon [51]. Almost universal genomic events include activation of the WNT signaling pathway and inactivation of the TGF- $\beta$ signaling pathway, leading to a subsequent increase of MYC activity, while genome changes often target the MAPK and PI3-K pathways but less frequently receptor tyrosine kinases [51]. Nevertheless, as not every mutation in driver genes is actually a driver itself, identifying cancer-drivers remains a key challenge, suggesting that, even though the expansion of the cancer driver gene corpus could be nearing the stages of completion, further systematic validation efforts are essential [52]. Additionally, high-volume research on rare variants associated with sporadic and familial CRC is still in its infancy, but promises to improve our understanding of the biological basis behind the disease and potentially inform future decision-making and drug development [42,43]. Quite notably, up to almost $75 \%$ of CRCs have been found to harbor potentially druggable single-nucleotide variants, indels or copy-number alterations [52], including targets within the WNT signaling, RTK/RAS and PI3K pathways [51] highlighting the utility and applicability of the basket design within patient-centric trials on targeted drug combinations. 
Table 1. Exploration of inter-patient genomic and transcriptional heterogeneity.

\begin{tabular}{|c|c|c|c|}
\hline Patients/Samples & Technology & Findings and Potential Clinical Implications & Ref. \\
\hline 5930 (18 cancer types) & WES & MSI-positive tumors were found in 14/18 cancer types and MSI had prognostic significance & [40] \\
\hline 4151 & $\begin{array}{l}\text { RNAseq, Affymetrix and Agilent gene } \\
\text { expression platforms }\end{array}$ & Four consensus molecular subtypes were identified potentially informing patient classification & [41] \\
\hline 1439 & WGS & 40 new independent association signals were discovered prompting further research for rare variants & [42] \\
\hline 1006 (familial) & WES & $\begin{array}{l}16 \% \text { of familial CRCs had highly penetrant rare mutations including } 3 \text { novel candidate cancer driver } \\
\text { genes (POT1, POLE2, MRE11) }\end{array}$ & [43] \\
\hline 999 (601 PTs, 533 MTs) & tNGS & $\begin{array}{l}\text { Right- and left-sided CRCs harbored distinct oncogenic mutations, potentially explaining differences } \\
\text { in survival }\end{array}$ & [44] \\
\hline 930 from 22 cancer types & WGS, RNAseq & $\begin{array}{l}\text { A network of } 193 \text { non-coding loci was identified, affecting gene expression and warranting further } \\
\text { research on functional mutation significance }\end{array}$ & [45] \\
\hline 921 (multiple GI cancer types) & WES & 5 major GI adenocarcinoma subtypes were identified, with potential prognostic relevance & [46] \\
\hline 511 from QUASAR 2 trial & tNGS & $\begin{array}{l}\text { TP53, KRAS, BRAF and GNAS mutations were independent adverse prognostic factors and total } \\
\text { mutation burden correlated with favorable survival, while MSI was not associated with survival }\end{array}$ & [47] \\
\hline 468 & tNGS $(1,321$ gene panel) & 17 genes correlated to prognosis and absence of $A P C$ mutations was associated with worse prognosis & [48] \\
\hline 341 & RNAseq & $\begin{array}{l}20 \text { dysregulated lncRNAs were identified, potentially related to tumorigenesis and/or progression, } 9 \text { of } \\
\text { which correlated to OS, and a CRC-specific RNA network was constructed }\end{array}$ & [49] \\
\hline 274 pts and mouse xenografts & WES, WGS & $\begin{array}{l}\text { CNA analysis revealed } 3 \text { clusters overlapping with consensus molecular subtypes and high } \\
\text { chromosomal instability predicted better response to BVZ combination therapy }\end{array}$ & [50] \\
\hline
\end{tabular}

- 24 genes were significantly mutated, some novel (ARID1A, SOX9, FAM123B/WTX)

276 pts 224 WES, 97 WGS, 215 RNAseq

- $\quad$ Potential drug targets: WNT signaling, $\beta$-catenin, IGF2, IGFR, ERBB2, ERBB3, MEK, AKT

and mTOR
argets. Whe

- Targetable recurrent CNAs: ERBB2 amplifications and a novel amplification of IGF2

\begin{tabular}{lll}
\hline 233 (4,742 from 21 cancer types) & WES & 4 novel genes with clear connections to cancer were identified \\
\hline 230 (9423 from 33 cancer types) & WES & $\begin{array}{l}\text { Up to 75\% of CRCs harbored drug targets, while 59 novel cancer drivers were identified in the } \\
\text { total cohort }\end{array}$ \\
\hline 213 pts and cell lines & WGS, ChIP-seq & $\begin{array}{l}\text { Functional non-coding point mutations at cohesin binding sites (CBSs) were frequent, similarly to other } \\
\text { cancers, putatively driving tumorigenesis }\end{array}$ \\
\hline $\begin{array}{l}\text { [56] } \\
\text { [06 pts plus organoids and }\end{array}$ & tNGS, WES, WGS, RNAseq & $\begin{array}{l}\text { Models retain genetic and transcriptomic tumor characteristics enabling research for improving } \\
\text { therapeutic response prediction }\end{array}$ \\
\hline 103 pts & tNGS, WES & 20 new recurrently mutated genes were identified \\
\hline
\end{tabular}

Abbreviations: chromatin immunoprecipitation sequencing (ChIP-seq), colorectal cacner (CRC), copy-number alteration (CNA), gastrointestinal (GI), long non-coding RNA (lncRNA), metastatic tumor (MT), microsatellite instability (MSI), next-generation sequencing (NGS), overall survival (OS), patients (pts), primary tumor (PT), RNA sequencing (RNAseq), targeted NGS (tNGS), whole-exome sequencing (WES), whole-genome sequencing (WGS). 
Next-generation sequencing has also enabled the development of novel putatively clinically meaningful tumor molecular sub-classifications, particularly via gene expression analysis with RNAseq [41,46,50]. For instance, Guinney and colleagues reported a robust CRC classification into four distinct consensus molecular subtypes (CMS), based on findings from six independent classification systems, including RNAseq and other omics technologies [41]. The sub-classes and their distinguishing features include the microsatellite instability immune subtype (CMS1, 14\%) which is hypermutated, microsatellite unstable with strong immune activation; the canonical subtype (CMS2, 37\%), which is epithelial featuring marked WNT and MYC signaling activation; the metabolic subtype (CMS3, 13\%), also epithelial with evident metabolic dysregulation; the mesenchymal subtype (CMS4, 23\%), showing prominent transforming growth factor- $\beta$ activation, stromal invasion and angiogenesis; and samples with miscellaneous features (13\%), which possibly reflect transitioning states or ITH. Regarding distinct clinical characteristics CMS1 tumors were frequently in female patients, right-sided and of higher histopathological grade, CMS2 cancers were mostly in the left colon and CMS4 CRCs were diagnosed at more advanced stages. Prognosis-wise, the CMS4 subtype was an independent adverse prognostic factor for overall and relapse-free survival, the CMS2 subtype was a favorable prognostic marker and the CMS1 subtype correlated to very poor survival after relapse [41]. Moreover, a comparative analysis of molecular subtypes among gastrointestinal adenocarcinomas revealed at least a partial overlap with CMS classes, irrespective of primary cancer localization from esophagus to rectum [46]. Although a clinically optimal cancer sub-classification informing patient stratification for drug trials remains remote, the CMS molecular classification represents a comprehensive step-wise process and the most vigorous effort to date, with both prognostic and predictive relevance [41,50]. Beyond systematic CRC classification, other independent prognostic markers include several mutated genes $[47,48]$ and primary tumor site of origin in the left or right colon associated with distinct genetic characteristics [44], while microsatellite instability has been confirmed as predictor of survival not only for CRC but across multiple other cancer types as well [40].

\subsection{Bulk Inter- and Intra-Tumor Heterogeneity}

Considering the simple acquisition of both primary and metastatic tumor specimens according to modern treatment guidelines, there have been several genomic studies investigating cancer heterogeneity both between and within tumors of the same individual, outlined in Table 2 [18,56-69]. Mutational concordance between matched primary and metastatic tumors was variable and dependable upon the sequencing method used, with exome and genome sequencing unveiling higher heterogeneity than $\mathrm{tNGS}[57,63]$. For instance, computationally performed sub-clonality analysis has revealed that the number of sub-clones was highly consistent between primary tumor and matched metastasis [56]. Moreover, targeted sequencing of available gene panels has revealed high mutational consistency for key cancer-associated and driver genes, as for example KRAS, NRAS, BRAF, APC, PIK3CA and SMAD4, suggesting that driver events occur early in evolution and that a single biopsy of either tumor possibly accurately recapitulates the cancer mutational landscape for drivers of tumorigenesis [57-59]. However, data support a mutation type-specific model of heterogeneity. More specifically, single-nucleotide variants have been found as highly stable between tumors of a single patient, whereas copy number alterations featured high variance both between as well as within individual patients, following a spatial pattern [18,59]. Nevertheless, despite low overall discordance between matched tumors, incremental changes are observed probably due to co-evolution. This suggests that a static biopsy alone is likely sufficient in the chemotherapy-naïve patient, but additional dynamic biopsies of both primary tumor and metastases may be necessary to precisely tailor further treatment following drug resistance [60-62]. By contrast, a small WGS study supported a model of late dissemination, reporting that almost $40 \%$ of mutations are primary tumor- or metastasis-specific, identifying several metastasis-specific oncotargets as well, further supporting dynamic sampling over treatment to individualize and tailor therapy to account for tumor evolution [63]. 
Table 2. Multiple biopsy next-generation sequencing dissecting tumor heterogeneity.

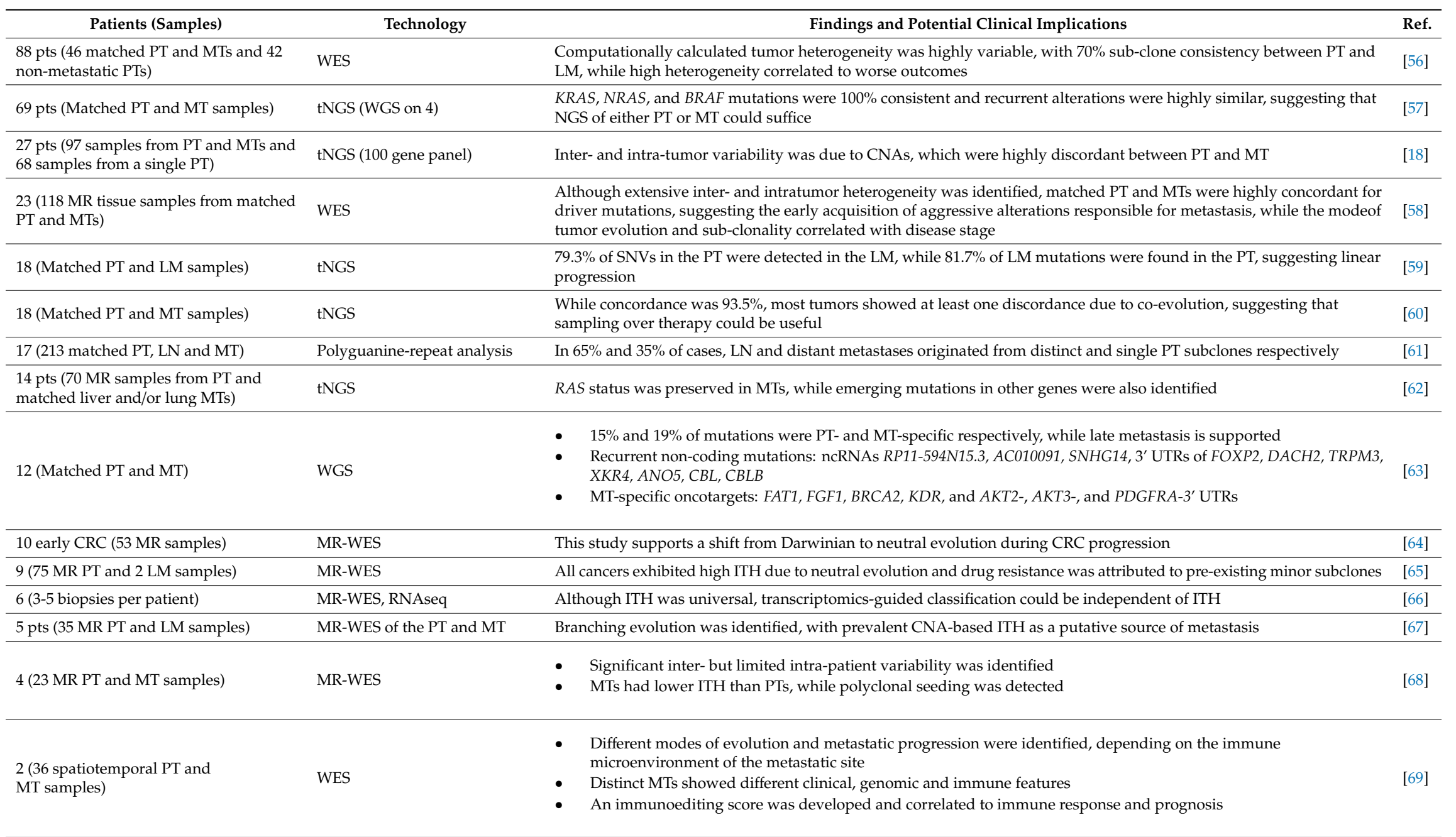

Abbreviations: colorectal cancer (CRC), copy-number alteration (CNA), intra-tumor heterogeneity (ITH), liver metastasis (LM), lymph node (LN), metastatic tumor (MT), multi-regional (MR), next-generation sequencing (NGS), non-coding RNA (ncRNA), patients (pts), primary tumor (PT), RNA sequencing (RNAseq), single-nucleotide variant (SNV), targeted NGS (tNGS), whole-exome sequencing (WES), whole-genome sequencing (WGS). 
In addition, distinct metastases have been found to harbor variant genomic architectures correlating to differential clinical outcomes, highlighting the potential to better optimize treatment via the molecular characterization of all patient tumors [69].

Intra-tumor heterogeneity was a universal finding, albeit at variable degrees. Hu et al., in a multi-regional WES study, revealed that both primary and metastatic tumors exhibited high levels of sub-clonality and ITH, indicating rapid temporal diversification [58]. In addition, the authors note that clonal evolution and selection is common at the early stages of tumorigenesis, contributing significantly to early dissemination and metastasis, and early identification of aggressive sub-clones could effectively guide more aggressive therapy [58]. Varying levels of intra-tumor heterogeneity of both primary tumors and metastases have also been demonstrated by several smaller studies integrating multi-regional sequencing $[18,65,68]$, as well as via computational reconstruction of tumor phylogenetic trees [56]. Transcriptional ITH in space has also been identified, but validation will be required in larger studies to extract safe conclusions on its potential significance [66]. However, the evolutionary principles governing the life history of CRC leading to ITH remain unclear. Available data are highly controversial between linear [69], branching according to Darwin's principles [61,67], and neutral [65] evolution, while some researchers propose a shift in the evolutionary history of CRC from Darwinian to neutral evolution during progression depending on tumor stage $[58,64]$. Taking into account the possibility of pre-existing minor aggressive sub-clones within the primary CRC [65] and the potential effect of the immune microenvironment on tumor evolution [69], further and more detailed exploration of cell-to-cell heterogeneity is required to delineate the complex mechanisms underlying tumorigenesis and metastasis

\subsection{Liquid Biopsies: Early Diagnosis, Drug Response Prediction and Patient Monitoring}

Lately, increasing interest has been concentrated on the evaluation of non-invasively acquired plasma samples, primarily aiming for biomarker identification and diagnosis through static NGS analysis cfDNA/ctDNA, as well as dissect dynamic cancer evolution and discover predictive markers via serial liquid biopsies over the course of therapy and during patient surveillance (Table 3) [19,22,70-77]. Apart from plasma cfDNA levels, which have traditionally been correlated to tumor burden, sequencing of cfDNA has been shown to accurately recapitulate the mutational landscape of the primary tumor [70]. More specifically, a very large-scale analysis on more than 20,000 oncologic patients with various late-stage cancers including CRC showed that tNGS of plasma cfDNA reliably detected tumor-derived alterations including major driver mutations, variants associated with drug resistance and clonal evolution in response to therapy as well as targetable mutations, detected in almost $20 \%$ of the total cohort [70]. Especially for colorectal cancer, Strickler et al. [19] reported that mutation frequencies identified by cfDNA-tNGS matched those of tumor sequencing studies and that tNGS liquid biopsies were capable of detecting alterations driving therapeutic resistance, potentially as a response to treatment. These results suggest the potential of large-scale $t$ NGS-based liquid biopsies to discover novel diagnostic, prognostic and predictive biomarkers or validate findings from smaller studies [73]. Quite notably, the use of ctDNA mutational profiles as predictive biomarkers has already entered the early clinical trial setting, and early results have showed that patient stratification and treatment with drug combinations matched to the individual circulating variability is a promising strategy to achieve disease control, following confirmation [22]. Regarding early diagnosis, despite moderate results in stages I-II from early efforts such as the CancerSEEK test [72], highly encouraging results have only recently been reported as an initial preliminary analysis of the Circulating Cell-free Genome Atlas (CCGA) (NCT02889978), a very large-scale clinical trial aiming to enroll 15,000 participants evaluating the diagnostic utility of targeted, whole-genome and whole-genome bisulfite sequencing of cfDNA [71]. For 12 major causes of cancer-related mortality, CRC among them, sensitivity was $77 \%$ and $84 \%$ for stages II and III respectively, although sensitivity was only $34 \%$ for stage I tumors. Detection rates for CRC in specific were up to $74 \%$ for stages I-III combined. Thus, final results are eagerly anticipated to determine the true diagnostic power of the blood test in the screening setting [71]. 
Table 3. Next-generation sequencing of circulating cell-free DNA: clinical utility.

\begin{tabular}{|c|c|c|c|}
\hline Patients (Samples) & Technology & Findings and Potential Clinical Implications & Ref. \\
\hline \multicolumn{4}{|c|}{ Static cf/ctDNA next-generation sequencing analysis } \\
\hline 21,807 (>50 advanced cancer types) & tNGS & $\begin{array}{l}\text { Driver gene cfDNA mutation profiles were similar to tumor NGS, while differences were attributed to clonal evolution } \\
\text { over therapy leading to resistance }\end{array}$ & [70] \\
\hline 1422 (sub-study, 21 tumor types) & tNGS, WGS, WGBS & Sensitivity for 12 cancers including CRC was $76 \%$ and $74 \%$ for stage I-III CRC & $\begin{array}{l}\text { NCT02889978 } \\
\text { [71] }\end{array}$ \\
\hline 1397 (advanced CRC) & tNGS & $\begin{array}{l}\text { Mutation frequencies in ctDNA were similar to tissue, and multiple distinct resistant mutations were identified in } \\
\text { single patients }\end{array}$ & [19] \\
\hline 1005 (8 cancer types) & CancerSEEK & Sensitivity was $65 \%$ and stage-dependent for CRC, suggesting the need for improvement before clinical applicability & [72] \\
\hline $\begin{array}{l}100 \text { (TARGET study, diverse advanced } \\
\text { cancers, } 23 \text { CRC) }\end{array}$ & tNGS & Druggable mutations were identified in $41 / 100 \mathrm{pts}, 11 / 41$ received matched therapy and all 11 achieved PR or stable disease & [22] \\
\hline $80 \mathrm{pts}$ & WGS & Recurrent CNVs were identified in multiple chromosomal regions and correlated with stage and prognosis & [73] \\
\hline \multicolumn{4}{|c|}{ Consecutive liquid biopsies before and after systemic therapy } \\
\hline $\begin{array}{l}261 \\
\text { (ASPECCT study, plasma samples before } \\
\text { and after panitumumab) }\end{array}$ & tNGS & $\begin{array}{l}\text { - Baseline high RAS mutant allele frequency and EGFR pathway mutations were adverse prognostic factors, while } \\
\text { tumor mutational burden increased over time } \\
\text { - This study suggests potential utility for primary and secondary decision-making }\end{array}$ & [74] \\
\hline $\begin{array}{l}238 \text { (ASPECCT study, plasma samples before } \\
\text { and after panitumumab) }\end{array}$ & tNGS & $\begin{array}{l}79 \% \text { of baseline samples were WT and } 21 \% \text { mutant RAS (associated with worse outcomes), while } 32 \% \text { of baseline-WT } \\
\text { tumors had emergent } R A S \text { mutations }\end{array}$ & [75] \\
\hline 53 (159 serial samples over chemotherapy) & tNGS & Mutational concordance between tumor and cfDNA was $92.3 \%$, while cfDNA levels were predictive of clinical response & [76] \\
\hline $\begin{array}{l}39 \text { various metastatic cancers, } 12 \text { CRC (159 } \\
\text { total serial samples over targeted therapy) }\end{array}$ & tNGS & $\begin{array}{l}\text { Monitoring of plasma mutation allele identified potential clonal responses to targeted therapy associated with } \\
\text { progression, suggesting potential prognostic and predictive utility }\end{array}$ & [77] \\
\hline
\end{tabular}

Abbreviations: cell-free DNA (cfDNA), circukating tumor DNA (ctDNA), colorectal cacner (CRC
whole-genome bisulfite sequencing (WGBS), whole-genome sequencing (WGS), wild-type (WT). 
Temporally collected serial liquid biopsies via cfDNA-NGS have been employed on the other hand in the search for a non-invasive tool enabling patient monitoring and potentially informing therapeutic decision-making. Earlier studies have already demonstrated the accuracy of cfDNA-NGS to identify tumor-specific mutations and correlated a reduction of cfDNA levels over therapy to clinical response and favorable outcomes [76]. Nevertheless, the exploration of spatiotemporal clonal evolution and the evaluation of emergent heterogeneity as a predictive biomarker via serial blood samples has only recently surfaced. For instance, Peeters and colleagues, in the ASPECCT study cohort of 261 patients with metastatic CRC, applied tNGS on cfDNA samples before and after panitumumab therapy to assess the predictive power of acquired RAS mutations [74]. Over anti-EGFR treatment approximately $20 \%$ of patients with wild-type KRAS at baseline featured emergent KRAS mutations as a response to therapy, often featuring multiple mutations in the same gene due to clonal evolution, highlighting a potential mechanism of acquired drug resistance. However, the authors underline that alternative drivers of resistance may exist outside the EGFR pathway, which were not captured by the limited 63-gene panel used in this study [74]. By contrast, a cfDNA-tNGS analysis conducted on a similar ASPECCT study subpopulation, despite noting the capacity of liquid biopsies to effectively monitor dynamic clonal cancer evolution, found that emergent RAS mutations lacked any association with patient outcomes and cannot be used as a predictive marker guiding decision-making on treatment, thus leaving room for controversy [75]. Furthermore, a smaller study demonstrated the capacity of serial liquid biopsies to track tumor dynamics and clonal responses to matched targeted therapy and predict time to disease progression, suggesting both prognostic and predictive utility [77]. Large-scale validation studies integrating much wider gene panels are hence required to establish the potential clinical applicability of serial NGS-based liquid biopsies for patient monitoring to readily predict therapeutic failure and disease relapse.

\subsection{Spatiotemporal Intra-Patient Heterogeneity}

On this basis, combined analysis of spatiotemporally collected matched tumor and plasma samples to identify intra-tumor and circulating heterogeneity respectively, which collectively comprise comprehensive intra-patient heterogeneity (Table 4) [17,20,78-82] currently represents the most promising strategy to explore tumor dynamics and identify markers predictive of drug resistance. One of the first efforts of comparative NGS analysis was performed by Siravegna et al. on 100 CRC patients [78]. Analysis of matched tumor and ctDNA during anti-EGFR targeted treatment uncovered mechanisms of secondary resistance to EGFR blockade and concluded that liquid biopsies could be a more robust alternative to tissue to track the genomic evolution of advanced CRC [78]. Concordant results have been reported for CRC under HER2 targeted therapy, namely trastuzumab and lapatinib. Most of the patients harbored drivers of resistance in plasma ctDNA and ctDNA-tNGS, such as mutations in ERBB2, RAS and PIK3CA, while liquid biopsies could detect therapeutic resistance with a sensitivity of over $85 \%$. Moreover, comparisons between the mutational landscapes of distinct metastases from a single patient revealed distinct evolutionary mechanisms and drug sensitivity profiles, suggesting that, contrary to current practice, serial plasma samples as well as multiregional sampling of both primary and all matched metastatic tumors is required to optimize treatment according to the integrated intra-patient mutational landscape [79]. Intra- and inter-lesion heterogeneity of resistance mechanisms has also been demonstrated by several small-scale studies, highlighting the necessity of appropriately designed spatiotemporal genomic trials to systematically explore dynamic tumor evolution and identify robust predictive biomarkers [80-82]. 
Table 4. Dynamic emergence of tumor heterogeneity and metastasis: clinical implication of intra-patient heterogeneity.

\begin{tabular}{|c|c|c|c|}
\hline Patients (Samples) & Technology & Findings and Potential Clinical Implications & Ref. \\
\hline $\begin{array}{l}100 \text { (Matched PT and plasma samples } \\
\text { after anti-EGFR) }\end{array}$ & BEAMing, tNGS & $\begin{array}{l}\text { Resistant circulating mutations were detected (KRAS, NRAS, MET, ERBB2, FLT3, EGFR, MAP2K1), while treatment } \\
\text { cessation led to re-emergence of sensitivity }\end{array}$ & [78] \\
\hline $\begin{array}{l}83 \text { diverse advanced cancers ( } 14 \text { CRC, Static } \\
\text { PT and ctDNA) }\end{array}$ & tNGS, ctDNA-tNGS & $\begin{array}{l}30 \% \text { of pts achieved disease control and targeting of more drug targets correlated with significantly favorable clinical } \\
\text { outcomes, supporting individualized drug combinations }\end{array}$ & $\begin{array}{l}\text { NCT02534675 } \\
{[20]}\end{array}$ \\
\hline $\begin{array}{l}47 \text { (archived PT, double MT samples at } \\
\text { baseline, PR and progression and serial } \\
\text { plasma samples) }\end{array}$ & tNGS, cfDNA-tNGS & $\begin{array}{l}\text { - } \quad 50 \% \text { of tumor } R A S-W T \text { patients harbor } R A S \text { mutations in baseline cfDNA } \\
\text { Dynamic tissue and liquid biopsies could predict primary and acquired cetuximab resistance and progression }\end{array}$ & $\begin{array}{c}\text { NCT02994888 } \\
\text { [17] }\end{array}$ \\
\hline $\begin{array}{l}33 \text { (Serial liquid biopsies over HER2 } \\
\text { blockade and diverse PT and MT samples) }\end{array}$ & WES, ctDNA-tNGS & $\begin{array}{l}E R B B 2, R A S \text { and } P I K 3 C A \text { mutations correlated to HER2-targeted therapy resistance and liquid biopsies identified primary } \\
\text { resistance with }>85 \% \text { sensitivity, suggesting utility for decision-making }\end{array}$ & [79] \\
\hline $\begin{array}{l}22 \text { (archived and post-progression tissue } \\
\text { after anti-EGFR and static ctDNA) }\end{array}$ & tNGS & $\begin{array}{l}\text { RAS mutations and } H E R 2 / M E T \text { amplification were the most prominent mechanisms of resistance in both tissue and } \\
\text { ctDNA, suggesting utility for decision-making }\end{array}$ & [80] \\
\hline 12 (Matched PT, MT and plasma samples) & tNGS & Limited concordance between ctDNA and PT/MT was identified, suggesting the need for refinement & [81] \\
\hline $\begin{array}{l}7 \text { (diverse tumor samples over anti-EGFR, } \\
\text { matched ctDNA, mouse xenografts) }\end{array}$ & $\begin{array}{l}\text { WES, WGS, CNA, } \\
\text { BEAMing }\end{array}$ & $M E T$ amplifications within rare pre-existing subclones confer resistance in KRAS-WT tumors during anti-EGFR therapy & [82] \\
\hline
\end{tabular}


As a result, the first early clinico-genomic trials are only just surfacing. The I-PREDICT study has already put the current paradigm of Precision Oncology trials to question, suggesting that individualized multi-drug targeting, as opposed to standard targeted monotherapies, sets the stage for future patient-centric trials [20]. Targeted NGS of both tumor and matched ctDNA samples successfully informed therapeutic decision-making in a large fraction of patients with various refractory cancers within a small cohort, improving disease control and survival rates and, in fact, in a pattern proportionate to the number of drugged alterations [20].

Moreover, Khan et al. [17] demonstrated the capacity of spatiotemporal multi-regional primary and progressive/metastatic tumor sampling, complemented by frequent serial cfDNA-NGS liquid biopsies during therapy, to predict time to therapeutic resistance and subsequent treatment failure, preceding clinical diagnosis, limiting however their primary scope on the RAS pathway [17]. Despite weaknesses, including the implementation of targeted NGS of a known gene panel, the focus on specific signaling pathways, the small sample sizes as well as the lack of a strict protocol, these studies represent early steps in the direction of spatiotemporal clinico-genomic studies exploring tumor evolution and potential implications of dynamic tumor heterogeneity for the clinic.

\subsection{Translational Implications of Cell-by-Cell Cancer Variability}

Multi-regional tumor profiling has indeed significantly advanced our understanding of intra-tumor heterogeneity and how it affects therapeutic response, cancer progression, metastasis and relapse. However, bulk genomic and transcriptomic profiling of a tumoral sample carries out only average measurements of cellular characteristics, thus masking critical aspects of ITH, such as rare resistant or aggressive cell subpopulations. Therefore, single-cell genomics and transcriptomics have surfaced as powerful approaches making possible the full and precise exploration of cellular properties at the level of individual cells [83]. Recent single-cell sequencing studies on CRC and their potential translational relevance are delineated in Table 5 [8,84-88]. Single-cell RNAseq has successfully improved upon existing CRC molecular classifications, via detecting distinct sub-clones within a single subtype previously identified through bulk tanscriptomics, with putative prognostic significance [85]. Additionally, single-cell multi-omics approaches have been utilized to trace epigenomic and transcriptomic dynamics of CRC, as well as potentially clinically relevant cell sub-clones associated with cancer progression and metastasis [84]. Most notably, an integrative single-cell analysis by Roerink and colleagues has revealed markedly differential responses to anti-cancer drugs owing to dynamic evolution, even between spatially and molecularly closely related cells within the same tumor [8]. These, along with further smaller studies [86-88], demonstrate the unprecedented power of integrated NGS systems to study the dynamics of the hallmarks of cancer and future research is eagerly anticipated to advance our understanding of tumor biology, as well as the origin and true phenotypic impact of cell-to-cell genomic, transcriptomic and epigenomic intra-tumoral variability. 
Table 5. Cell-to-cell heterogeneity and drug response prediction.

\begin{tabular}{|c|c|c|c|}
\hline Patients/Samples & Technology & Findings and Potential Translational Implications & Ref. \\
\hline $\begin{array}{l}12 \text { pts (1,900 single cells and bulk } \\
\text { multi-regional PT and MT) }\end{array}$ & $\begin{array}{l}\text { Multiomics including single-cell } \\
\text { Trio-seq and bulk MR-WGS }\end{array}$ & $\begin{array}{l}\text { - Several cellular genetic subclones were identified with PTs featuring more extensive subclonality than MTs } \\
\text { - Single-cell multiomics can track tumor dynamics during progression and metastasis }\end{array}$ & {$[84]$} \\
\hline $\begin{array}{l}11 \text { pts and } 7 \text { cell lines ( } 590 \text { patient-derived } \\
\text { and } 561 \text { cell line-derived single cells) }\end{array}$ & $\begin{array}{l}\text { Single-cell RNAseq and RCA } \\
\text { algorithm }\end{array}$ & $\begin{array}{l}\text { Single-cell transcriptomics enabled more detailed sub-classification of CRC subtypes than bulk RNAseq, correlating } \\
\text { to prognosis }\end{array}$ & [85] \\
\hline 3 pts (Single cell-derived clonal organoids) & tNGS, WGS, RNAseq & $\begin{array}{l}\text { All three colorectal cancers contained cells resistant to common drugs, while drug sensitivity was variable even among } \\
\text { closely related single cell-derived clones, suggesting late emergence of resistance }\end{array}$ & [8] \\
\hline $\begin{array}{l}2 \text { pts ( } 6 \text { bulk samples and } 336 \text { single cells } \\
\text { from CRC, normal epithelium and polyps) }\end{array}$ & WES, single-cell WES & $\begin{array}{l}\text { - Adenoma and cancer were monoclonal, albeit with distinct mutational landscapes, with cancers further diversifying } \\
\text { into distinct subclones } \\
\text { - } 3 \text { new driver mutations were identified (OR1B1, LAMA1, ADCY3) }\end{array}$ & [86] \\
\hline $\begin{array}{l}2 \text { pts ( } 360 \text { single-cells and bulk PT and } \\
\text { LM samples) }\end{array}$ & Single-cell tNGS, bulk WES & $\begin{array}{l}\text { Monoclonal and polyclonal seeding was identified, while rare cell sub-populations were found to correlate with } \\
\text { progression and metastasis, although a late-dissemination model was identified }\end{array}$ & {$[87]$} \\
\hline 1 pt (63 single cells) & WES & $\begin{array}{l}\text { Two distinct clones were identified, one major with early APC and TP53 mutations and one minor with CDC27 and } \\
\text { PABPC1 mutations, highlighting the ability of single-cell NGS to identify rare mutations }\end{array}$ & {$[88]$} \\
\hline
\end{tabular}

Abbreviations: colorectal cancer (CRC), liver metastasis (LM), metastatic tumor (MT), multi-regional (MR), next-generation sequencing (NGS), patient (pt), primary tumor (PT), reference component analysis (RCA), RNA sequencing (RNAseq), targeted NGS (tNGS), whole-exome sequencing (WES), whole-genome sequencing (WGS). 


\subsection{Functional Non-Coding Mutations and Regulatory Network Exploration}

It has been now well established that more than $90 \%$ of variants associated with common diseases, including cancer, lie within the non-coding areas of the genome [89]. However, the effects of non-coding sequence alterations on gene expression remain poorly understood [45]. Beyond genome-wide association studies [89], modern genome and transcriptome sequencing analyses have identified recurrent non-coding aberrations affecting regulatory circuitry in colorectal cancer, with putative prognostic significance $[49,63]$. Moreover, innovative research has identified regulatory networks comprised by several non-coding elements, mutations in which deregulate the expression of target genes irrespective of tumor type, some of which have not been identified as cancer drivers [45]. Therefore, future research is greatly motivated to better characterize the architecture of transcriptional networks and the regulation of gene expression and further elucidate on the role of non-coding functional mutations in cancer.

\section{Future Perspectives}

In the era of genome and transcriptome exploration in time and space towards Cancer Precision Medicine, NGS systems have a pivotal role in overcoming cancer challenges. Intra-tumor heterogeneity at both bulk and single-cell resolution has emerged as a prognostic and predictive biomarker, potentially informing individualized therapy. Moreover, simultaneous NGS of matched serial cfDNA/ctDNA could further increase the accuracy of drug response prediction.

Another significant NGS implication is the capacity to discover new druggable mutations [52,90], to expand the list of approved targeted drugs, addressing extensive genetic, genomic and transcriptional heterogeneity. On this basis, the selection of most effective drug combinations matched to the comprehensive intra-patient heterogeneity, combining intra-tumoral and circulating variability, could allow for optimal individualized therapy. However, these promising data call for validation before wide clinical implementation.

\subsection{Emerging Clinical Trials in Precision Oncology}

Early cancer diagnosis is the most crucial independent factor for improved overall survival, or even reaching cure. Regarding CRC in particular, survival after treatment for localized disease is approximately $90 \%$ [13]. Although colonoscopy remains the gold standard for early diagnosis of CRC, the available figures for cancer statistics for the United States suggest no increase in localized disease detection rates over the past decade $[13,91]$. Apparently, compliance for asymptomatic individuals over 50 years old remains quite low. Therefore, the discovery of a non-invasive test could dramatically increase early diagnosis. A rational research strategy has focused on the development of blood test screening tools. Next-generation sequencing of circulating cfDNA/ctDNA has already returned promising data, but the minute amounts of cfDNA associated with small primary tumors remains challenging to detect. Several studies have recently been published, but only two have provided exciting findings. First, the underway large-scale clinical trial "The Circulating Cell-free Genome Atlas" (NCT02889978) has reported encouraging early results on 1,422 patients with various cancer types, including CRC. Sensitivity for stage I-III CRC was $74 \%$, but since most patients had stage II-IV cancer, the final results should be anticipated to assess the true efficacy of the test in early-stage, asymptomatic individuals [71]. And second, much more groundbreaking data on early non-invasive diagnosis have been reported by Cristiano et al. [29]. More specifically, sensitivity for stages I-II of several cancer types, including CRC, was $79 \%$ and the combination of targeted and whole-genome sequencing with machine learning achieved overall detection rates of over $90 \%$, highlighting the potential for blood screening following validation clinical trials [29].

Rapid advances in NGS, particularly tNGS on a panel of known genes, have already led to the completion of early-phase trials [17,20-22], with more still underway [92]. However, despite promising published data on survival benefits via drug combinations within the basket trial design, further 
randomized controlled trials are required to draw definitive conclusions. Moreover, fundamental evidence on dynamic genomic clonal evolution [93] has created major clinical expectations for genomic trials of spatiotemporal design [94] unraveling the clinical utility of ITH and matched NGS of serial liquid biopsies comprising comprehensive dynamic intra-patient heterogeneity [95]. This sophisticated clinical trial framework could not only validate the predictive capacity of intra-tumor and matched circulating mutational landscape, but also support the evidence-based discovery of novel oncotargets and drugs [96]. In Figure 1 we propose a step-wise approach to validate prognostic and predictive biomarkers, as well as new biomarker-directed drugs.

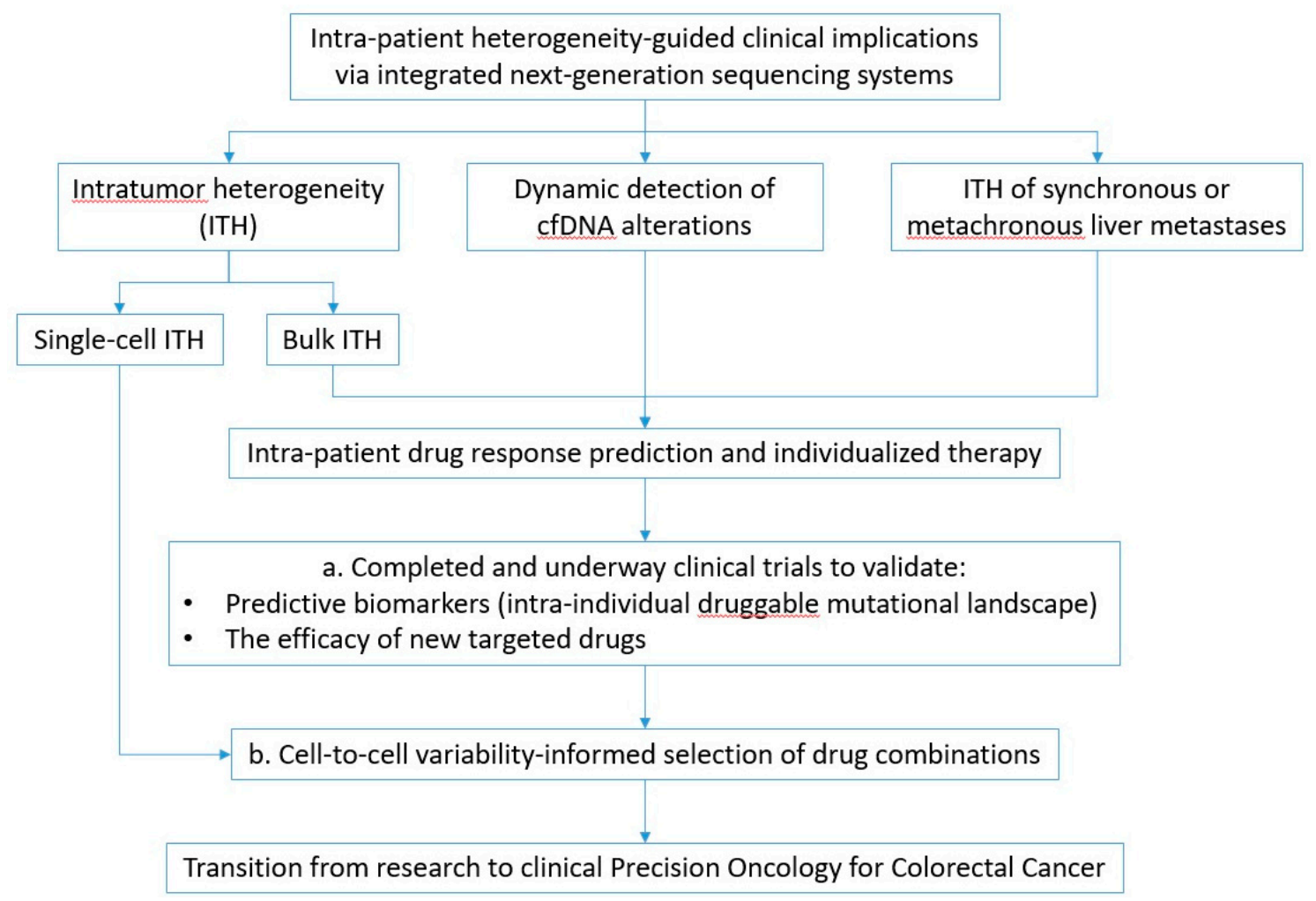

Figure 1. Putative clinical implications emerging from the breakthrough exploration of intra-patient intratumor and circulating heterogeneity. (a) Step-wise delineation of translational and clinical implications via genome and transcriptome sequencing. (b) Medium-term clinical expectations: Progress from genomic and transcriptomic studies to sequencing of bulk multi-regional primary and metastatic tumor tissue and matched serial cfDNA within appropriately designed clinical trials promises to realize the initial phase of Precision Oncology. Innovative future translational research: Emerging advances in single-cell exploration of genomic and transcriptional heterogeneity could enable the precise selection of drug combinations.

\subsection{Pharmacogenomic Predictions at the Single-Cell Level: A New Horizon for Cancer Precision Medicine}

Tremendous progress from bulk multi-regional tissue NGS to genome and transcriptome sequencing of hundreds of thousands single cells has opened new horizons towards the realization of the long-term researchers' dream to accurately predict response to multiple drug combinations, including agents targeting both cancer and stromal cells [8,97]. Considering the hundreds millions of malignant and non-malignant cells comprising a solid tumor, recent successful exploration of the transcriptional landscapes of two million individual cells applying machine learning algorithms [2] highlights the future feasibility of full cell-by-cell intra-tumor variability characterization integrating artificial intelligence, towards individualized therapeutic response prediction. 
More recently, pioneering technological combinations of single-cell NGS, CRISPR-Cas and Hi-C is transforming biomedical research, raising high hopes for understanding linear and non-linear interactions controlling gene expression at single-cell resolution [98].

\subsection{Transcriptional Networks and Pharmaceutical Controllability}

Evidence from genome-wide association studies on most disease- and cancer-associated variants residing outside of protein-coding genes [89] and the ENCODE project on the functionality of most of the non-coding genome [32] guides molecular fundamental research towards understanding regulatory networks and gene expression control. Recent studies implementing breakthrough combinations of WGS to identify functional non-coding mutations, RNAseq, ChIP-seq, Hi-C, genome/transcriptome engineering and single-cell NGS have provided deeper insights into regulatory mechanisms governing the expression of interacting genes [98-101]. Despite this groundbreaking progress, further sophisticated research is needed to accurately characterize driver alterations and key regulators of transcriptional networks, towards the controllability of aberrant dynamic linear and non-linear circuitry with next-generation therapies [102-104].

\section{Conclusions}

The validity of NGS systems in the exploration of genome- and transcriptome-wide heterogeneity is transforming biomedical and cancer research and highlights the new era of patient-centric genomic trials. Evidence-based clinical treatment with drug combinations within tNGS-based basket trials has already provided promising results. Ongoing and future spatiotemporal genomic and transcriptomic trials evaluating and potentially validating bulk ITH and matched cfDNA variability could establish both the discovery of new targeted drugs and the development of predictive biomarkers for individualized drug sensitivity-directed therapy. With a more distant perspective, progress in cell-to-cell heterogeneity-guided drug selection could enable optimized multi-targeted therapy matched to the comprehensive intra-patient druggable mutational landscape.

Author Contributions: All authors have made substantial contributions to the work, have approved the final submitted version and agree to be accountable for the accuracy and integrity of the manuscript.

Funding: The authors report no funding assistance.

Conflicts of Interest: The authors declare no conflict of interest.

\section{References}

1. Shendure, J.; Balasubramanian, S.; Church, G.M.; Gilbert, W.; Rogers, J.; Schloss, J.A.; Waterston, R.H. DNA sequencing at 40: Past, present and future. Nature 2017, 550, 345-353. [CrossRef] [PubMed]

2. Cao, J.; Spielmann, M.; Qiu, X.; Huang, X.; Ibrahim, D.M.; Hill, A.J.; Zhang, F.; Mundlos, S.; Christiansen, L.; Steemers, F.J.; et al. The single-cell transcriptional landscape of mammalian organogenesis. Nature 2019, 566, 496-502. [CrossRef] [PubMed]

3. Elkon, R.; Agami, R. Characterization of noncoding regulatory DNA in the human genome. Nat. Biotechnol. 2017, 35, 732-746. [CrossRef] [PubMed]

4. Haendel, M.A.; Chute, C.G.; Robinson, P.N. Classification, Ontology, and Precision Medicine. N. Engl. J. Med. 2018, 379, 1452-1462. [CrossRef] [PubMed]

5. Bedard, P.L.; Hansen, A.R.; Ratain, M.J.; Siu, L.L. Tumour heterogeneity in the clinic. Nature 2013, 501, 355-364. [CrossRef]

6. Swanton, C.; Soria, J.C.; Bardelli, A.; Biankin, A.; Caldas, C.; Chandarlapaty, S.; de Koning, L.; Dive, C.; Feunteun, J.; Leung, S.Y.; et al. Consensus on precision medicine for metastatic cancers: A report from the MAP conference. Ann. Oncol. 2016, 27, 1443-1448. [CrossRef]

7. Lawrence, M.S.; Stojanov, P.; Mermel, C.H.; Robinson, J.T.; Garraway, L.A.; Golub, T.R.; Meyerson, M.; Gabriel, S.B.; Lander, E.S.; Getz, G. Discovery and saturation analysis of cancer genes across 21 tumour types. Nature 2014, 505, 495-501. [CrossRef] 
8. Roerink, S.F.; Sasaki, N.; Lee-Six, H.; Young, M.D.; Alexandrov, L.B.; Behjati, S.; Mitchell, T.J.; Grossmann, S.; Lightfoot, H.; Egan, D.A.; et al. Intra-tumour diversification in colorectal cancer at the single-cell level. Nature 2018, 556, 457-462. [CrossRef]

9. Ben-David, U.; Siranosian, B.; Ha, G.; Tang, H.; Oren, Y.; Hinohara, K.; Strathdee, C.A.; Dempster, J.; Lyons, N.J.; Burns, R.; et al. Genetic and transcriptional evolution alters cancer cell line drug response. Nature 2018, 560, 325-330. [CrossRef]

10. Kyrochristos, I.D.; Ziogas, D.E.; Roukos, D.H. Drug resistance: Origins, evolution and characterization of genomic clones and the tumor ecosystem to optimize precise individualized therapy. Drug Discov. Today 2019, 24, 1281-1294. [CrossRef]

11. Klein, C.A. Selection and adaptation during metastatic cancer progression. Nature 2013, 501, 365-372. [CrossRef] [PubMed]

12. Orlando, G.; Law, P.J.; Cornish, A.J.; Dobbins, S.E.; Chubb, D.; Broderick, P.; Litchfield, K.; Hariri, F.; Pastinen, T.; Osborne, C.S.; et al. Promoter capture Hi-C-based identification of recurrent noncoding mutations in colorectal cancer. Nat. Genet. 2018, 50, 1375-1380. [CrossRef] [PubMed]

13. Siegel, R.L.; Miller, K.D.; Jemal, A. Cancer statistics, 2019. CA Cancer J. Clin. 2019, 69, 7-34. [CrossRef] [PubMed]

14. National Comprehensive Cancer Network. Available online: https://www.nccn.org/ (accessed on 22 October 2019).

15. The national cancer act of 1971. J. Natl. Cancer Inst. 1972, 48, 577-584.

16. Bray, F.; Ferlay, J.; Soerjomataram, I.; Siegel, R.L.; Torre, L.A.; Jemal, A. Global cancer statistics 2018: GLOBOCAN estimates of incidence and mortality worldwide for 36 cancers in 185 countries. CA Cancer J. Clin. 2018, 68, 394-424. [CrossRef] [PubMed]

17. Khan, K.H.; Cunningham, D.; Werner, B.; Vlachogiannis, G.; Spiteri, I.; Heide, T.; Mateos, J.F.; Vatsiou, A.; Lampis, A.; Damavandi, M.D.; et al. Longitudinal Liquid Biopsy and Mathematical Modeling of Clonal Evolution Forecast Time to Treatment Failure in the PROSPECT-C Phase II Colorectal Cancer Clinical Trial. Cancer Discov. 2018, 8, 1270-1285. [CrossRef] [PubMed]

18. Mamlouk, S.; Childs, L.H.; Aust, D.; Heim, D.; Melching, F.; Oliveira, C.; Wolf, T.; Durek, P.; Schumacher, D.; Blaker, H.; et al. DNA copy number changes define spatial patterns of heterogeneity in colorectal cancer. Nat. Commun. 2017, 8, 14093. [CrossRef] [PubMed]

19. Strickler, J.H.; Loree, J.M.; Ahronian, L.G.; Parikh, A.R.; Niedzwiecki, D.; Pereira, A.A.L.; McKinney, M.; Korn, W.M.; Atreya, C.E.; Banks, K.C.; et al. Genomic Landscape of Cell-Free DNA in Patients with Colorectal Cancer. Cancer Discov. 2018, 8, 164-173. [CrossRef] [PubMed]

20. Sicklick, J.K.; Kato, S.; Okamura, R.; Schwaederle, M.; Hahn, M.E.; Williams, C.B.; De, P.; Krie, A.; Piccioni, D.E.; Miller, V.A.; et al. Molecular profiling of cancer patients enables personalized combination therapy: The I-PREDICT study. Nat. Med. 2019, 25, 744. [CrossRef]

21. Rodon, J.; Soria, J.C.; Berger, R.; Miller, W.H.; Rubin, E.; Kugel, A.; Tsimberidou, A.; Saintigny, P.; Ackerstein, A.; Brana, I.; et al. Genomic and transcriptomic profiling expands precision cancer medicine: The WINTHER trial. Nat. Med. 2019, 25, 751. [CrossRef]

22. Rothwell, D.G.; Ayub, M.; Cook, N.; Thistlethwaite, F.; Carter, L.; Dean, E.; Smith, N.; Villa, S.; Dransfield, J.; Clipson, A.; et al. Utility of ctDNA to support patient selection for early phase clinical trials: The TARGET study. Nat. Med. 2019, 25, 738. [CrossRef] [PubMed]

23. Torre, L.A.; Bray, F.; Siegel, R.L.; Ferlay, J.; Lortet-Tieulent, J.; Jemal, A. Global cancer statistics, 2012. CA Cancer J. Clin. 2015, 65, 87-108. [CrossRef] [PubMed]

24. Crick, F. Central dogma of molecular biology. Nature 1970, 227, 561-563. [CrossRef] [PubMed]

25. Rask-Andersen, M.; Almen, M.S.; Schioth, H.B. Trends in the exploitation of novel drug targets. Nat. Rev. Drug Discov. 2011, 10, 579-590. [CrossRef]

26. Amin, M.B.; American Joint Committee on Cancer. AJCC Cancer Staging Manual, 8th ed.; Springer: New, York, NY, USA, 2017; p. xvii. 1024 p.

27. Bosset, J.F.; Calais, G.; Mineur, L.; Maingon, P.; Stojanovic-Rundic, S.; Bensadoun, R.J.; Bardet, E.; Beny, A.; Ollier, J.C.; Bolla, M.; et al. Fluorouracil-based adjuvant chemotherapy after preoperative chemoradiotherapy in rectal cancer: Long-term results of the EORTC 22921 randomised study. Lancet Oncol. 2014, 15, 184-190. [CrossRef] 
28. Alberts, S.R.; Sargent, D.J.; Nair, S.; Mahoney, M.R.; Mooney, M.; Thibodeau, S.N.; Smyrk, T.C.; Sinicrope, F.A.; Chan, E.; Gill, S.; et al. Effect of oxaliplatin, fluorouracil, and leucovorin with or without cetuximab on survival among patients with resected stage III colon cancer: A randomized trial. JAMA 2012, 307, 1383-1393. [CrossRef]

29. Kerr, R.S.; Love, S.; Segelov, E.; Johnstone, E.; Falcon, B.; Hewett, P.; Weaver, A.; Church, D.; Scudder, C.; Pearson, S.; et al. Adjuvant capecitabine plus bevacizumab versus capecitabine alone in patients with colorectal cancer (QUASAR 2): An open-label, randomised phase 3 trial. Lancet Oncol. 2016, 17, 1543-1557. [CrossRef]

30. Primrose, J.; Falk, S.; Finch-Jones, M.; Valle, J.; O’Reilly, D.; Siriwardena, A.; Hornbuckle, J.; Peterson, M.; Rees, M.; Iveson, T.; et al. Systemic chemotherapy with or without cetuximab in patients with resectable colorectal liver metastasis: The New EPOC randomised controlled trial. Lancet Oncol. 2014, 15, 601-611. [CrossRef]

31. European Society for Medical Oncology. Available online: https://www.esmo.org/ (accessed on 22 October 2019).

32. Consortium, E.P. An integrated encyclopedia of DNA elements in the human genome. Nature 2012, 489, 57-74. [CrossRef]

33. Yue, F.; Cheng, Y.; Breschi, A.; Vierstra, J.; Wu, W.; Ryba, T.; Sandstrom, R.; Ma, Z.; Davis, C.; Pope, B.D.; et al. A comparative encyclopedia of DNA elements in the mouse genome. Nature 2014, 515, 355-364. [CrossRef]

34. Mod, E.C.; Roy, S.; Ernst, J.; Kharchenko, P.V.; Kheradpour, P.; Negre, N.; Eaton, M.L.; Landolin, J.M.; Bristow, C.A.; Ma, L.; et al. Identification of functional elements and regulatory circuits by Drosophila modENCODE. Science 2010, 330, 1787-1797. [CrossRef]

35. The Cancer Genome Atlas Program-National Cancer Institute. Available online: https://www.cancer.gov/ about-nci/organization/ccg/research/structural-genomics/tcga (accessed on 13 October 2019).

36. International Cancer Genome Consortium. Available online: https://icgc.org/ (accessed on 16 October 2019).

37. Wang, Z.; Gerstein, M.; Snyder, M. RNA-Seq: A revolutionary tool for transcriptomics. Nat. Rev. Genet. 2009, 10, 57-63. [CrossRef] [PubMed]

38. Bailey, P.; Chang, D.K.; Nones, K.; Johns, A.L.; Patch, A.M.; Gingras, M.C.; Miller, D.K.; Christ, A.N.; Bruxner, T.J.; Quinn, M.C.; et al. Genomic analyses identify molecular subtypes of pancreatic cancer. Nature 2016, 531, 47-52. [CrossRef] [PubMed]

39. Park, P.J. ChIP-seq: Advantages and challenges of a maturing technology. Nat. Rev. Genet. 2009, 10, 669-680. [CrossRef] [PubMed]

40. Hause, R.J.; Pritchard, C.C.; Shendure, J.; Salipante, S.J. Classification and characterization of microsatellite instability across 18 cancer types. Nat. Med. 2016, 22, 1342-1350. [CrossRef]

41. Guinney, J.; Dienstmann, R.; Wang, X.; de Reynies, A.; Schlicker, A.; Soneson, C.; Marisa, L.; Roepman, P.; Nyamundanda, G.; Angelino, P.; et al. The consensus molecular subtypes of colorectal cancer. Nat. Med. 2015, 21, 1350-1356. [CrossRef]

42. Huyghe, J.R.; Bien, S.A.; Harrison, T.A.; Kang, H.M.; Chen, S.; Schmit, S.L.; Conti, D.V.; Qu, C.; Jeon, J.; Edlund, C.K.; et al. Discovery of common and rare genetic risk variants for colorectal cancer. Nat. Genet. 2019, 51, 76-87. [CrossRef]

43. Chubb, D.; Broderick, P.; Dobbins, S.E.; Frampton, M.; Kinnersley, B.; Penegar, S.; Price, A.; Ma, Y.P.; Sherborne, A.L.; Palles, C.; et al. Rare disruptive mutations and their contribution to the heritable risk of colorectal cancer. Nat. Commun. 2016, 7, 11883. [CrossRef]

44. Yaeger, R.; Chatila, W.K.; Lipsyc, M.D.; Hechtman, J.F.; Cercek, A.; Sanchez-Vega, F.; Jayakumaran, G.; Middha, S.; Zehir, A.; Donoghue, M.T.A.; et al. Clinical Sequencing Defines the Genomic Landscape of Metastatic Colorectal Cancer. Cancer Cell 2018, 33, 125-136. [CrossRef]

45. Zhang, W.; Bojorquez-Gomez, A.; Velez, D.O.; Xu, G.; Sanchez, K.S.; Shen, J.P.; Chen, K.; Licon, K.; Melton, C.; Olson, K.M.; et al. A global transcriptional network connecting noncoding mutations to changes in tumor gene expression. Nat. Genet. 2018, 50, 613-620. [CrossRef]

46. Liu, Y.; Sethi, N.S.; Hinoue, T.; Schneider, B.G.; Cherniack, A.D.; Sanchez-Vega, F.; Seoane, J.A.; Farshidfar, F.; Bowlby, R.; Islam, M.; et al. Comparative Molecular Analysis of Gastrointestinal Adenocarcinomas. Cancer Cell 2018, 33, 721-735. [CrossRef] [PubMed] 
47. Domingo, E.; Camps, C.; Kaisaki, P.J.; Parsons, M.J.; Mouradov, D.; Pentony, M.M.; Makino, S.; Palmieri, M.; Ward, R.L.; Hawkins, N.J.; et al. Mutation burden and other molecular markers of prognosis in colorectal cancer treated with curative intent: Results from the QUASAR 2 clinical trial and an Australian community-based series. Lancet Gastroenterol. Hepatol. 2018, 3, 635-643. [CrossRef]

48. Schell, M.J.; Yang, M.; Teer, J.K.; Lo, F.Y.; Madan, A.; Coppola, D.; Monteiro, A.N.; Nebozhyn, M.V.; Yue, B.; Loboda, A.; et al. A multigene mutation classification of 468 colorectal cancers reveals a prognostic role for APC. Nat. Commun. 2016, 7, 11743. [CrossRef] [PubMed]

49. Li, F.; Li, Q.; Wu, X. Construction and analysis for differentially expressed long non-coding RNAs and MicroRNAs mediated competing endogenous RNA network in colon cancer. PLoS ONE 2018, 13, e0192494. [CrossRef] [PubMed]

50. Smeets, D.; Miller, I.S.; O'Connor, D.P.; Das, S.; Moran, B.; Boeckx, B.; Gaiser, T.; Betge, J.; Barat, A.; Klinger, R.; et al. Copy number load predicts outcome of metastatic colorectal cancer patients receiving bevacizumab combination therapy. Nat. Commun. 2018, 9, 4112. [CrossRef]

51. Cancer Genome Atlas, N. Comprehensive molecular characterization of human colon and rectal cancer. Nature 2012, 487, 330-337. [CrossRef]

52. Bailey, M.H.; Tokheim, C.; Porta-Pardo, E.; Sengupta, S.; Bertrand, D.; Weerasinghe, A.; Colaprico, A.; Wendl, M.C.; Kim, J.; Reardon, B.; et al. Comprehensive Characterization of Cancer Driver Genes and Mutations. Cell 2018, 173, 371-385. [CrossRef]

53. Katainen, R.; Dave, K.; Pitkanen, E.; Palin, K.; Kivioja, T.; Valimaki, N.; Gylfe, A.E.; Ristolainen, H.; Hanninen, U.A.; Cajuso, T.; et al. CTCF/cohesin-binding sites are frequently mutated in cancer. Nat. Genet. 2015, 47, 818-821. [CrossRef]

54. Schutte, M.; Risch, T.; Abdavi-Azar, N.; Boehnke, K.; Schumacher, D.; Keil, M.; Yildiriman, R.; Jandrasits, C.; Borodina, T.; Amstislavskiy, V.; et al. Molecular dissection of colorectal cancer in pre-clinical models identifies biomarkers predicting sensitivity to EGFR inhibitors. Nat. Commun. 2017, 8, 14262. [CrossRef]

55. Guda, K.; Veigl, M.L.; Varadan, V.; Nosrati, A.; Ravi, L.; Lutterbaugh, J.; Beard, L.; Willson, J.K.; Sedwick, W.D.; Wang, Z.J.; et al. Novel recurrently mutated genes in African American colon cancers. Proc. Natl. Acad. Sci. USA 2015, 112, 1149-1154. [CrossRef]

56. Joung, J.G.; Oh, B.Y.; Hong, H.K.; Al-Khalidi, H.; Al-Alem, F.; Lee, H.O.; Bae, J.S.; Kim, J.; Cha, H.U.; Alotaibi, M.; et al. Tumor Heterogeneity Predicts Metastatic Potential in Colorectal Cancer. Clin. Cancer Res. 2017, 23, 7209-7216. [CrossRef] [PubMed]

57. Brannon, A.R.; Vakiani, E.; Sylvester, B.E.; Scott, S.N.; McDermott, G.; Shah, R.H.; Kania, K.; Viale, A.; Oschwald, D.M.; Vacic, V.; et al. Comparative sequencing analysis reveals high genomic concordance between matched primary and metastatic colorectal cancer lesions. Genome Biol. 2014, 15, 454. [CrossRef] [PubMed]

58. Hu, Z.; Ding, J.; Ma, Z.; Sun, R.; Seoane, J.A.; Scott Shaffer, J.; Suarez, C.J.; Berghoff, A.S.; Cremolini, C.; Falcone, A.; et al. Quantitative evidence for early metastatic seeding in colorectal cancer. Nat. Genet. 2019, 51, 1113-1122. [CrossRef] [PubMed]

59. Tan, I.B.; Malik, S.; Ramnarayanan, K.; McPherson, J.R.; Ho, D.L.; Suzuki, Y.; Ng, S.B.; Yan, S.; Lim, K.H.; Koh, D.; et al. High-depth sequencing of over 750 genes supports linear progression of primary tumors and metastases in most patients with liver-limited metastatic colorectal cancer. Genome Biol. 2015, 16, 32. [CrossRef] [PubMed]

60. Kim, R.; Schell, M.J.; Teer, J.K.; Greenawalt, D.M.; Yang, M.; Yeatman, T.J. Co-evolution of somatic variation in primary and metastatic colorectal cancer may expand biopsy indications in the molecular era. PLOS ONE 2015, 10, e0126670. [CrossRef] [PubMed]

61. Naxerova, K.; Reiter, J.G.; Brachtel, E.; Lennerz, J.K.; van de Wetering, M.; Rowan, A.; Cai, T.; Clevers, H.; Swanton, C.; Nowak, M.A.; et al. Origins of lymphatic and distant metastases in human colorectal cancer. Science 2017, 357, 55-60. [CrossRef] [PubMed]

62. Kovaleva, V.; Geissler, A.L.; Lutz, L.; Fritsch, R.; Makowiec, F.; Wiesemann, S.; Hopt, U.T.; Passlick, B.; Werner, M.; Lassmann, S. Spatio-temporal mutation profiles of case-matched colorectal carcinomas and their metastases reveal unique de novo mutations in metachronous lung metastases by targeted next generation sequencing. Mol. Cancer 2016, 15, 63. [CrossRef] 
63. Ishaque, N.; Abba, M.L.; Hauser, C.; Patil, N.; Paramasivam, N.; Huebschmann, D.; Leupold, J.H.; Balasubramanian, G.P.; Kleinheinz, K.; Toprak, U.H.; et al. Whole genome sequencing puts forward hypotheses on metastasis evolution and therapy in colorectal cancer. Nat. Commun. 2018, 9, 4782. [CrossRef]

64. Saito, T.; Niida, A.; Uchi, R.; Hirata, H.; Komatsu, H.; Sakimura, S.; Hayashi, S.; Nambara, S.; Kuroda, Y.; Ito, S.; et al. A temporal shift of the evolutionary principle shaping intratumor heterogeneity in colorectal cancer. Nat. Commun. 2018, 9, 2884. [CrossRef]

65. Uchi, R.; Takahashi, Y.; Niida, A.; Shimamura, T.; Hirata, H.; Sugimachi, K.; Sawada, G.; Iwaya, T.; Kurashige, J.; Shinden, Y.; et al. Integrated Multiregional Analysis Proposing a New Model of Colorectal Cancer Evolution. PLoS Genet. 2016, 12, e1005778. [CrossRef]

66. Arnadottir, S.S.; Jeppesen, M.; Lamy, P.; Bramsen, J.B.; Nordentoft, I.; Knudsen, M.; Vang, S.; Madsen, M.R.; Thastrup, O.; Thastrup, J.; et al. Characterization of genetic intratumor heterogeneity in colorectal cancer and matching patient-derived spheroid cultures. Mol. Oncol. 2018, 12, 132-147. [CrossRef] [PubMed]

67. Kim, T.M.; Jung, S.H.; An, C.H.; Lee, S.H.; Baek, I.P.; Kim, M.S.; Park, S.W.; Rhee, J.K.; Lee, S.H.; Chung, Y.J. Subclonal Genomic Architectures of Primary and Metastatic Colorectal Cancer Based on Intratumoral Genetic Heterogeneity. Clin. Cancer Res. 2015, 21, 4461-4472. [CrossRef] [PubMed]

68. Wei, Q.; Ye, Z.; Zhong, X.; Li, L.; Wang, C.; Myers, R.E.; Palazzo, J.P.; Fortuna, D.; Yan, A.; Waldman, S.A.; et al. Multiregion whole-exome sequencing of matched primary and metastatic tumors revealed genomic heterogeneity and suggested polyclonal seeding in colorectal cancer metastasis. Ann. Oncol. 2017, 28, 2135-2141. [CrossRef] [PubMed]

69. Angelova, M.; Mlecnik, B.; Vasaturo, A.; Bindea, G.; Fredriksen, T.; Lafontaine, L.; Buttard, B.; Morgand, E.; Bruni, D.; Jouret-Mourin, A.; et al. Evolution of Metastases in Space and Time under Immune Selection. Cell 2018, 175, 751-765. [CrossRef] [PubMed]

70. Zill, O.A.; Banks, K.C.; Fairclough, S.R.; Mortimer, S.A.; Vowles, J.V.; Mokhtari, R.; Gandara, D.R.; Mack, P.C.; Odegaard, J.I.; Nagy, R.J.; et al. The Landscape of Actionable Genomic Alterations in Cell-Free Circulating Tumor DNA from 21,807 Advanced Cancer Patients. Clin. Cancer Res. 2018, 24, 3528-3538. [CrossRef] [PubMed]

71. GRAIL. Available online: https://grail.com/press-releases/grail-announces-positive-new-data-with-multicancer-early-detection-blood-test-from-ccga-study/ (accessed on 27 September 2019).

72. Cohen, J.D.; Li, L.; Wang, Y.; Thoburn, C.; Afsari, B.; Danilova, L.; Douville, C.; Javed, A.A.; Wong, F.; Mattox, A.; et al. Detection and localization of surgically resectable cancers with a multi-analyte blood test. Science 2018, 359, 926-930. [CrossRef] [PubMed]

73. Li, J.; Dittmar, R.L.; Xia, S.; Zhang, H.; Du, M.; Huang, C.C.; Druliner, B.R.; Boardman, L.; Wang, L. Cell-free DNA copy number variations in plasma from colorectal cancer patients. Mol. Oncol. 2017, 11, 1099-1111. [CrossRef]

74. Peeters, M.; Price, T.; Boedigheimer, M.; Kim, T.W.; Ruff, P.; Gibbs, P.; Thomas, A.; Demonty, G.; Hool, K.; Ang, A. Evaluation of Emergent Mutations in Circulating Cell-Free DNA and Clinical Outcomes in Patients with Metastatic Colorectal Cancer Treated with Panitumumab in the ASPECCT Study. Clin. Cancer Res. 2019, 25, 1216-1225. [CrossRef]

75. Kim, T.W.; Peeters, M.; Thomas, A.; Gibbs, P.; Hool, K.; Zhang, J.; Ang, A.L.; Bach, B.A.; Price, T. Impact of Emergent Circulating Tumor DNA RAS Mutation in Panitumumab-Treated Chemoresistant Metastatic Colorectal Cancer. Clin. Cancer Res. 2018, 24, 5602-5609. [CrossRef]

76. Tie, J.; Kinde, I.; Wang, Y.; Wong, H.L.; Roebert, J.; Christie, M.; Tacey, M.; Wong, R.; Singh, M.; Karapetis, C.S.; et al. Circulating tumor DNA as an early marker of therapeutic response in patients with metastatic colorectal cancer. Ann. Oncol. 2015, 26, 1715-1722. [CrossRef]

77. Frenel, J.S.; Carreira, S.; Goodall, J.; Roda, D.; Perez-Lopez, R.; Tunariu, N.; Riisnaes, R.; Miranda, S.; Figueiredo, I.; Nava-Rodrigues, D.; et al. Serial Next-Generation Sequencing of Circulating Cell-Free DNA Evaluating Tumor Clone Response to Molecularly Targeted Drug Administration. Clin. Cancer Res. 2015, 21, 4586-4596. [CrossRef] [PubMed]

78. Siravegna, G.; Mussolin, B.; Buscarino, M.; Corti, G.; Cassingena, A.; Crisafulli, G.; Ponzetti, A.; Cremolini, C.; Amatu, A.; Lauricella, C.; et al. Clonal evolution and resistance to EGFR blockade in the blood of colorectal cancer patients. Nat. Med. 2015, 21, 795-801. [CrossRef] [PubMed] 
79. Siravegna, G.; Lazzari, L.; Crisafulli, G.; Sartore-Bianchi, A.; Mussolin, B.; Cassingena, A.; Martino, C.; Lanman, R.B.; Nagy, R.J.; Fairclough, S.; et al. Radiologic and Genomic Evolution of Individual Metastases during HER2 Blockade in Colorectal Cancer. Cancer Cell 2018, 34, 148-162. [CrossRef] [PubMed]

80. Pietrantonio, F.; Vernieri, C.; Siravegna, G.; Mennitto, A.; Berenato, R.; Perrone, F.; Gloghini, A.; Tamborini, E.; Lonardi, S.; Morano, F.; et al. Heterogeneity of Acquired Resistance to Anti-EGFR Monoclonal Antibodies in Patients with Metastatic Colorectal Cancer. Clin. Cancer Res. 2017, 23, 2414-2422. [CrossRef] [PubMed]

81. Beije, N.; Helmijr, J.C.; Weerts, M.J.; Beaufort, C.M.; Wiggin, M.; Marziali, A.; Verhoef, C.; Sleijfer, S.; Jansen, M.P.; Martens, J.W. Somatic mutation detection using various targeted detection assays in paired samples of circulating tumor DNA, primary tumor and metastases from patients undergoing resection of colorectal liver metastases. Mol. Oncol. 2016, 10, 1575-1584. [CrossRef] [PubMed]

82. Bardelli, A.; Corso, S.; Bertotti, A.; Hobor, S.; Valtorta, E.; Siravegna, G.; Sartore-Bianchi, A.; Scala, E.; Cassingena, A.; Zecchin, D.; et al. Amplification of the MET receptor drives resistance to anti-EGFR therapies in colorectal cancer. Cancer Discov. 2013, 3, 658-673. [CrossRef] [PubMed]

83. Suva, M.L.; Tirosh, I. Single-Cell RNA Sequencing in Cancer: Lessons Learned and Emerging Challenges. Mol. Cell 2019, 75, 7-12. [CrossRef]

84. Bian, S.; Hou, Y.; Zhou, X.; Li, X.; Yong, J.; Wang, Y.; Wang, W.; Yan, J.; Hu, B.; Guo, H.; et al. Single-cell multiomics sequencing and analyses of human colorectal cancer. Science 2018, 362, 1060-1063. [CrossRef]

85. Li, H.; Courtois, E.T.; Sengupta, D.; Tan, Y.; Chen, K.H.; Goh, J.J.L.; Kong, S.L.; Chua, C.; Hon, L.K.; Tan, W.S.; et al. Reference component analysis of single-cell transcriptomes elucidates cellular heterogeneity in human colorectal tumors. Nat. Genet. 2017, 49, 708-718. [CrossRef]

86. Wu, H.; Zhang, X.Y.; Hu, Z.; Hou, Q.; Zhang, H.; Li, Y.; Li, S.; Yue, J.; Jiang, Z.; Weissman, S.M.; et al. Evolution and heterogeneity of non-hereditary colorectal cancer revealed by single-cell exome sequencing. Oncogene 2017, 36, 2857-2867. [CrossRef]

87. Leung, M.L.; Davis, A.; Gao, R.; Casasent, A.; Wang, Y.; Sei, E.; Vilar, E.; Maru, D.; Kopetz, S.; Navin, N.E. Single-cell DNA sequencing reveals a late-dissemination model in metastatic colorectal cancer. Genome Res. 2017, 27, 1287-1299. [CrossRef] [PubMed]

88. Yu, C.; Yu, J.; Yao, X.; Wu, W.K.; Lu, Y.; Tang, S.; Li, X.; Bao, L.; Li, X.; Hou, Y.; et al. Discovery of biclonal origin and a novel oncogene SLC12A5 in colon cancer by single-cell sequencing. Cell Res. 2014, 24, 701-712. [CrossRef] [PubMed]

89. Maurano, M.T.; Humbert, R.; Rynes, E.; Thurman, R.E.; Haugen, E.; Wang, H.; Reynolds, A.P.; Sandstrom, R.; $\mathrm{Qu}, \mathrm{H}$.; Brody, J.; et al. Systematic localization of common disease-associated variation in regulatory DNA. Science 2012, 337, 1190-1195. [CrossRef] [PubMed]

90. Dewey, F.E.; Murray, M.F.; Overton, J.D.; Habegger, L.; Leader, J.B.; Fetterolf, S.N.; O'Dushlaine, C.; Van Hout, C.V.; Staples, J.; Gonzaga-Jauregui, C.; et al. Distribution and clinical impact of functional variants in 50,726 whole-exome sequences from the DiscovEHR study. Science 2016, 354, aaf6814. [CrossRef] [PubMed]

91. Jemal, A.; Siegel, R.; Ward, E.; Hao, Y.; Xu, J.; Thun, M.J. Cancer statistics, 2009. CA Cancer J. Clin. 2009, 59, 225-249. [CrossRef]

92. ClinicalTrials.gov. Available online: https://clinicaltrials.gov/ (accessed on 7 October 2019).

93. Eirew, P.; Steif, A.; Khattra, J.; Ha, G.; Yap, D.; Farahani, H.; Gelmon, K.; Chia, S.; Mar, C.; Wan, A.; et al. Dynamics of genomic clones in breast cancer patient xenografts at single-cell resolution. Nature 2015, 518, 422-426. [CrossRef]

94. Roukos, D.H. Spatiotemporal diversification of intrapatient genomic clones and early drug development concepts realize the roadmap of precision cancer medicine. Drug Discov. Today 2017, 22, 1148-1164. [CrossRef]

95. Zhang, Y.; Chang, L.; Yang, Y.; Fang, W.; Guan, Y.; Wu, A.; Hong, S.; Zhou, H.; Chen, G.; Chen, X.; et al. Intratumor heterogeneity comparison among different subtypes of non-small-cell lung cancer through multi-region tissue and matched ctDNA sequencing. Mol. Cancer 2019, 18, 7. [CrossRef]

96. Kyrochristos, I.D.; Roukos, D.H. Comprehensive intra-individual genomic and transcriptional heterogeneity: Evidence-based Colorectal Cancer Precision Medicine. Cancer Treat. Rev. 2019, 80, 101894. [CrossRef]

97. Ligorio, M.; Sil, S.; Malagon-Lopez, J.; Nieman, L.T.; Misale, S.; Di Pilato, M.; Ebright, R.Y.; Karabacak, M.N.; Kulkarni, A.S.; Liu, A.; et al. Stromal Microenvironment Shapes the Intratumoral Architecture of Pancreatic Cancer. Cell 2019, 178, 160-175. [CrossRef] 
98. Gasperini, M.; Hill, A.J.; McFaline-Figueroa, J.L.; Martin, B.; Kim, S.; Zhang, M.D.; Jackson, D.; Leith, A.; Schreiber, J.; Noble, W.S.; et al. A Genome-wide Framework for Mapping Gene Regulation via Cellular Genetic Screens. Cell 2019, 176, 377-390. [CrossRef] [PubMed]

99. Delaneau, O.; Zazhytska, M.; Borel, C.; Giannuzzi, G.; Rey, G.; Howald, C.; Kumar, S.; Ongen, H.; Popadin, K.; Marbach, D.; et al. Chromatin three-dimensional interactions mediate genetic effects on gene expression. Science 2019, 364, eaat8266. [CrossRef] [PubMed]

100. Han, K.; Jeng, E.E.; Hess, G.T.; Morgens, D.W.; Li, A.; Bassik, M.C. Synergistic drug combinations for cancer identified in a CRISPR screen for pairwise genetic interactions. Nat. Biotechnol. 2017, 35, 463-474. [CrossRef] [PubMed]

101. Raj, B.; Wagner, D.E.; McKenna, A.; Pandey, S.; Klein, A.M.; Shendure, J.; Gagnon, J.A.; Schier, A.F. Simultaneous single-cell profiling of lineages and cell types in the vertebrate brain. Nat. Biotechnol. 2018, 36, 442-450. [CrossRef] [PubMed]

102. Roukos, D.H. Crossroad between linear and nonlinear transcription concepts in the discovery of next-generation sequencing systems-based anticancer therapies. Drug Discov. Today 2016, 21, 663-673. [CrossRef] [PubMed]

103. Dugger, S.A.; Platt, A.; Goldstein, D.B. Drug development in the era of precision medicine. Nat. Rev. Drug Discov. 2018, 17, 183-196. [CrossRef]

104. Bashor, C.J.; Patel, N.; Choubey, S.; Beyzavi, A.; Kondev, J.; Collins, J.J.; Khalil, A.S. Complex signal processing in synthetic gene circuits using cooperative regulatory assemblies. Science 2019, 364, 593-597. [CrossRef]

(C) 2019 by the authors. Licensee MDPI, Basel, Switzerland. This article is an open access article distributed under the terms and conditions of the Creative Commons Attribution (CC BY) license (http://creativecommons.org/licenses/by/4.0/). 